\title{
Comparison of nasal cannulas and the OxyArm in patients requiring chronic domiciliary oxygen therapy
}

\author{
James Paul BSc MD MSc FRCPC 1 , Ted Otvos BSc RRT RRCP2
}

\begin{abstract}
J Paul, T Otvos. Comparison of nasal cannulas and the OxyArm in patients requiring chronic domiciliary oxygen therapy. Can Respir J 2006;13(8):421-426.
\end{abstract}

OBJECTIVES: The present study was designed to compare the performance of a new oxygen delivery device, the OxyArm (OA) (Southmedic Inc, Canada), with a standard nasal cannula (NC) (Salter-Style 1600, Salter Labs, USA) for both oxygen delivery and patient preference in patients on long-term oxygen therapy (LTOT). DESIGN AND SETTING: Randomized crossover study conducted in an outpatient setting.

PATIENTS AND METHODS: Twenty-five clinically stable LTOT patients were randomly assigned to an oxygen device ( $\mathrm{NC}$ or $\mathrm{OA}$ ) sequence. The baseline saturation level was determined, and patients were then treated at oxygen flow rates of $2 \mathrm{~L} / \mathrm{min}, 3 \mathrm{~L} / \mathrm{min}, 4 \mathrm{~L} / \mathrm{min}$, $5 \mathrm{~L} / \mathrm{min}, 6 \mathrm{~L} / \mathrm{min}$ and $7 \mathrm{~L} / \mathrm{min}$ for $10 \mathrm{~min}$ each while at rest. Patients were then crossed over to the second device and the procedure was repeated. Oximetry values were then obtained following a 5 min walk test using the same device sequence. Lastly, the patients were sent home for a four-week home OA trial, after which, they filled out a questionnaire.

RESULTS: This sample of patients was primarily elderly ex-smokers with severe chronic obstructive pulmonary disease on oxygen therapy for the majority of the day. The primary findings were that the $\mathrm{OA}$ and $\mathrm{NC}$ were equally effective in delivering oxygen to patients and maintaining their oxygen saturation at both rest $(\mathrm{P}=0.82)$ and during a 5 min walk test $(\mathrm{P}=0.83)$. A patient's personal experience and comfort were identified as the most important factors in deciding on an oxygen device. Most patients felt that the OA was most suited for oxygen therapy while at rest.

CONCLUSIONS: The OA proved to be similar to the NC in delivering oxygen and maintaining saturation in patients on LTOT. The $\mathrm{OA}$ is one of the few alternatives to using NCs for these patients and, with its current design, appears to be most suited for resting conditions.

Key Words: Crossover study; Long-term care; Medical device; Nasal cannulas; OxyArm; Oxygen inhalation therapy; Patient preference; Pulse oximetry

\section{La comparaison des canules nasales avec l'OxyArm chez les patients ayant besoin d'oxygénothérapie chronique à domicile}

OBJECTIFS : La présente étude a été conçue pour comparer le rendement d'un nouvel appareil d'administration d'oxygène, OxyArm (OA) (Southmedic Inc., Canada) et d'une canule nasale standard (CN) (SalterStyle 1600, Salter Labs, États-Unis), tant pour ce qui est de l'administration d'oxygène que de la préférence des patients dans le cadre de l'oxygénothérapie prolongée (OTP)

CONCEPTION ET MILIEU : Étude aléatoire transversale mené en milieu ambulatoire.

PATIENTS ET MÉTHODOLOGIE : Vingt-cinq patients sous OTP cliniquement stables ont reçu aléatoirement un appareil d'oxygène $(\mathrm{CN}$ ou $\mathrm{OA}$ ). On a déterminé leur taux de saturation au départ, puis on les a traités à des débits d'oxygène de $2 \mathrm{~L} / \mathrm{min}, 3 \mathrm{~L} / \mathrm{min}, 4 \mathrm{~L} / \mathrm{min}, 5 \mathrm{~L} / \mathrm{min}$, $6 \mathrm{~L} / \mathrm{min}$ et $7 \mathrm{~L} / \mathrm{min}$ au repos, pendant dix minutes dans chaque cas. On a ensuite repris l'opération après avoir transféré les patients à l'autre appareil. On a relevé les valeurs saturométriques après un test de marche de cinq minutes, selon la même séquence d'appareil. Enfin, les patients ont fait l'essai de l'OA pendant quatre semaines à la maison, puis ont répondu à un sondage.

RÉSULTATS : Cet échantillon de patients se composait surtout d'anciens fumeurs âgés atteints d'une maladie pulmonaire obstructive chronique grave, sous oxygénothérapie pendant la majeure partie de la journée. D'après les observations primaires, l'OA et la $\mathrm{CN}$ étaient tout aussi efficaces pour l'administration d'oxygène aux patients et pour maintenir leur saturation d'oxygène au repos $(\mathrm{P}=0,82)$ et pendant un test de marche de cinq minutes $(\mathrm{P}=0,83)$. On a établi que l'expérience personnelle et le sentiment d'aise du patient représentaient les facteurs les plus importants pour choisir l'appareil d'oxygénothérapie. La plupart des patients trouvaient l'OA mieux adapté à l'oxygénothérapie au repos. CONCLUSIONS : L'OA assurait une administration d'oxygène et le maintien d'une saturation en oxygène similaires à ceux de la $\mathrm{CN}$ chez les patients sous OTP. L'OA est l'une des rares solutions de rechange à la CN chez ces patients et, selon sa conception actuelle, il semble mieux adapté en période de repos.
$\mathrm{T}$ wo large randomized trials in the early 1980s showed that long-term oxygen therapy (LTOT) improves survival in patients with advanced disease (1-3). Other patients with hypoxemia secondary to other forms of lung disease or heart failure are also likely to have a survival benefit from LTOT $(4,5)$. Currently, there are over one million people on LTOT worldwide, and the use of this therapy varies by geographical region (6). In Ontario (population 12 million), there are more than 15,000 patients who are receiving LTOT (4).
Oxygen can be delivered to patients by using a variety of facemasks, nasal catheters, nasal cannulas (NCs) and transtracheal catheters (7). The majority of patients on LTOT use NCs. They are convenient and generally well tolerated, but they have been shown to deliver variable fractions of inspired oxygen both within and between patients, and there are some troublesome side effects, including drying, irritation, infection, and bleeding of nasal mucous membranes (8-11). Recently, the OxyArm (OA) (Southmedic Inc, Canada), a new minimal 


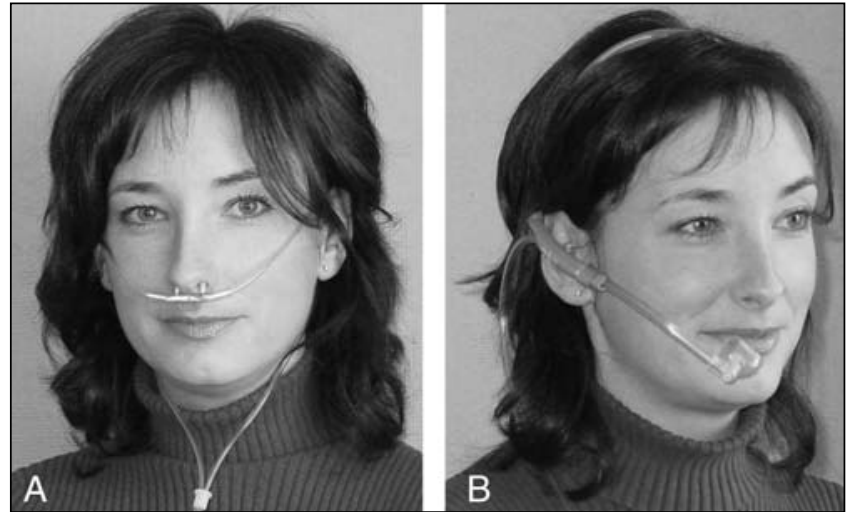

Figure 1) The oxygen delivery devices tested - A Nasal cannula (SalterStyle 1600, Salter Labs, USA); B OxyArm (Southmedic Inc, Canada)

contact oxygen delivery system, was developed (12). The OA is a device that was modelled after the headsets used for hands-free telecommunications devices. The device consists of a U-shaped headset that traverses across the top of the head, an oxygen supply line attached to an adjustable boom, and an oxygen diffuser that is directed toward the face. The boom is attached to the headband by a ball-and-socket joint that can be adjusted for individual patients.

A previous study documented that saturation levels by pulse oximetry in chronic obstructive pulmonary disease (COPD) patients at rest were equivalent in those being delivered oxygen via the $\mathrm{OA}$ and in those receiving oxygen via an $\mathrm{NC}(8)$. However, this study had some methodological limitations.

The purpose of the present study was to further clarify whether the OA is as effective as an NC (Salter-Style 1600, Salter Labs, USA) in maintaining oxygen saturation levels in patients on chronic LTOT. In addition, the present study obtained subjective feedback from patients on their preferences for oxygen delivery devices. The study is important for helping physicians and patients to select the most appropriate oxygen delivery device for their needs.

\section{PATIENTS AND METHODS}

\section{Study design and sample size determination}

Research ethics board approval was obtained from the Royal Victoria Hospital (Barrie, Ontario). The study used a randomized crossover design. The necessary sample size (for equivalency in pulse oximetry performance) was determined to be 25 patients, assuming a power of $80 \%$, a significance level of $5 \%$ and a minimum clinically significant difference in oxygen saturation of $2 \%$. This difference was chosen because of the error inherent in the measurement of oxygen saturation with pulse oximeters. The standard deviation of the difference in saturation between the two devices was estimated from a pilot study involving five patients.

\section{Patient recruitment}

Patients living in the vicinity of Barrie, Ontario (population 100,000 ), who were receiving home oxygen and who were clinically stable with no hospitalization or upper respiratory tract illness in the previous four weeks, were recruited for the study. Patients who were younger than 18 years of age were excluded from the study.

\section{Baseline assessment and randomization}

A respiratory therapist (RT) met with each of the patients in an outpatient setting, reviewed the study protocol, obtained informed consent, and then completed a questionnaire that assessed the patient's past medical history and background regarding previous oxygen treatment. The most recent spirometry results were obtained from the patient's family physician and/or the Health Records Department of the Royal Victoria Hospital. To establish the baseline saturation level, each patient was seated comfortably for 15 min while breathing room air, and the minimum saturation level was recorded. If the saturation level dropped to $82 \%$ or lower, the baseline assessment was stopped before $15 \mathrm{~min}$ and this value was recorded as the baseline.

Patients were randomly assigned to the order in which they received oxygen therapy by either an $\mathrm{NC}$ or the OA. The oxygen delivery systems tested are shown in Figure 1. The randomization sequence was obtained from a computerized random number generator, and the resulting treatment allocations specified which device to use first. The treatment allocation sequence was concealed using opaque envelopes and they were numbered sequentially.

Throughout the study period, the RT monitored the patients. Pulse oximetry and heart rate were monitored continuously, and respiratory rate was assessed by examination every $5 \mathrm{~min}$. In addition, the patients were instructed to notify the RT if they felt unwell at any time during the study.

\section{Oxygen treatment at rest}

After the baseline saturation was reached, the first device (either $\mathrm{OA}$ or NC) was applied to the patient. In the case of the OA, the device was applied with the headpiece over the top of the head and the arms traversing in front of the ears; the oxygen tubing boom was adjusted such that the diffuser sat approximately $2 \mathrm{~cm}$ in front of the mouth. The headband was adjusted to fit snugly to ensure that the OA did not migrate with movement. Before starting the oxygen treatment, the RT determined the pattern of breathing (nasal, mouth, both nasal and mouth, or unable to determine) by examination. Oxygen was then administered at $2 \mathrm{~L} / \mathrm{min}$ for $10 \mathrm{~min}$. At the end of the treatment period, five consecutive saturation values, $10 \mathrm{~s}$ apart, were printed from the oximeter. The mean of these measurements was taken as the outcome to account for short-term variability in recording and to limit observational bias on the part of the RT. Saturation levels were obtained in a similar fashion for oxygen flow rates of $3 \mathrm{~L} / \mathrm{min}$, $4 \mathrm{~L} / \mathrm{min}, 5 \mathrm{~L} / \mathrm{min}, 6 \mathrm{~L} / \mathrm{min}$ and $7 \mathrm{~L} / \mathrm{min}$. Patients were not returned to their baseline saturation between sequential increases in oxygen flow rates.

After the first treatment period, the patients were returned to their baseline saturation by having them breathe room air for $15 \mathrm{~min}$. At this point, the patients were crossed over to the second device (OA or $\mathrm{NC}$ ) and the RT re-established the baseline saturation. The saturation levels were again determined at the six different oxygen flow levels in the same manner as before.

\section{Exercise testing: The 5 min walk test}

After the measurements at rest were completed, the patients were returned to their baseline saturation by breathing room air for $15 \mathrm{~min}$. The first device was then applied to the patient, and oxygen was administered at his or her prescribed flow rate. Patients were encouraged to walk at their own pace in a corridor on level ground for $5 \mathrm{~min}$, or until limited by shortness of breath or fatigue. At the end, the distance covered by the patient was measured and five sequential saturation levels, $10 \mathrm{~s}$ apart, were recorded. At this point, the patient was allowed to rest while receiving oxygen for $10 \mathrm{~min}$. 
TABLE 1

\section{Characteristics of the study patients}

\begin{tabular}{lc}
\hline Sex & \\
Males, $\mathrm{n}(\%)$ & $16(64)$ \\
Females, $\mathrm{n}(\%)$ & $9(36)$ \\
Mean age, years $(95 \% \mathrm{Cl})$ & $69.9(63.4$ to 76.5$)$ \\
Mean weight, $\mathrm{kg}(95 \% \mathrm{Cl})$ & $70.1(63.2$ to 77.0$)$ \\
Mean height, $\mathrm{cm}(95 \% \mathrm{Cl})$ & $168.5(162.8$ to 174.2$)$ \\
Indication for home oxygen therapy, $\mathrm{n}(\%)$ & \\
Chronic obstructive pulmonary disease & $22(88)$ \\
Restrictive lung disease & $1(4)$ \\
Lung cancer & $1(4)$ \\
Lung metastases & $1(4)$ \\
Smoking status, $\mathrm{n}(\%)$ & \\
Smoker & $0(0)$ \\
Ex-smoker & $22(88)$ \\
Nonsmoker & $3(12)$ \\
Spirometry, mean (95\% Cl ${ }^{*}$ & \\
Forced expiratory volume in $1 \mathrm{~s}, \mathrm{~L}$ & $1.05(0.77$ to 1.33$)$ \\
Forced vital capacity, $\mathrm{L}$ & $1.90(1.53$ to 2.26$)$ \\
Oxygen prescription & \\
Mean duration of treatment, years $(95 \% \mathrm{Cl})$ & $1.3(1.1$ to 1.6$)$ \\
Mean hours per day $(95 \% \mathrm{Cl})$ & $22.8(20.9$ to 24.0$)$ \\
Mean oxygen flow rate, $\mathrm{L} /$ min $(95 \% \mathrm{Cl})$ & $2.7(2.5$ to 3.0$)$ \\
Satisfied with nasal cannula, $\mathrm{n}(\%)$ & $17(68)$ \\
\hline Spirmetry &
\end{tabular}

*Spirometry results were available for only 13 of the patients

The baseline saturation was re-established by breathing room air for $15 \mathrm{~min}$, and the patient was then crossed over to the second device (OA or NC). The distance travelled and the saturation level after $5 \mathrm{~min}$ of walking was determined as before. If the patient's saturation level dropped below $82 \%$ or if they requested, the exercise period was stopped before $5 \mathrm{~min}$.

At the end of the treatment period, the patients were given a questionnaire to complete regarding their opinion of the two devices.

\section{Four-week home OA trial}

Following the acute oxygen treatment trial, the patients were sent home with the OA for a four-week trial. The patients were instructed how to position the device, and were asked to try the device while at rest and during activity. The patients were given a diary to record comments and the number of hours that they used the device each day. Following the trial period, each patient was contacted and a structured questionnaire was completed.

\section{Statistical methods}

Data are presented as means (95\% CIs) unless stated otherwise. Pulse oximeter saturation percentages represent a mean of five consecutive readings recorded digitally at $10 \mathrm{~s}$ intervals. For all tests, significance was assumed at $\mathrm{P}<0.05$. The analysis was conducted with SPSS 11.0 (SPSS Inc, USA). For comparison of oximetry values between oxygen devices, oxygen flow rates, device order and breathing patterns, a univariate ANOVA was used. The Tukey Honestly Significant Differences multiple comparison test was used to compare oximetry levels at the different oxygen flow rates. Student's $t$ test for paired data was used to compare baseline oximetry values with room air across the first and second periods. $\chi^{2}$ analysis was used to compare preference frequencies from the questionnaire results.

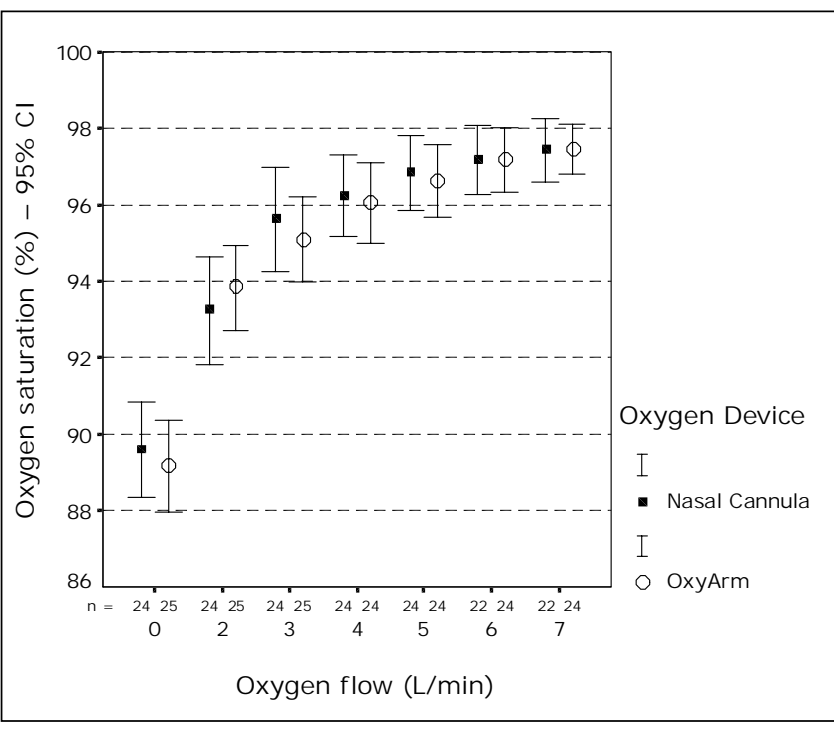

Figure 2) Per cent oxygen saturation versus oxygen flow rate for the OxyArm (OA) (Southmedic Inc, Canada) and nasal cannula (NC) (Salter-Style 1600, Salter Labs, USA). ANOVA showed that the oxygen delivery device (OA or NC) did not significantly affect the saturation level. For both the OA and NC, the device order did not affect the saturation level. Post hoc multiple comparisons of saturation levels at the various flow rates using the Tukey honestly significant differences test showed that the saturation level increased significantly from baseline up to a flow rate of $3 \mathrm{~L} / \mathrm{min}$, after which there was no significant increase in the saturation

\section{RESULTS}

One hundred fifteen potentially eligible patients were contacted, of whom 25 met the inclusion criteria and agreed to participate. Resting oximetry data and questionnaire data were available for all patients, and exercise data were available for 24 patients (one patient declined to exercise after the study had begun). Table 1 presents the characteristics of the patients who participated, including age, weight, height, reason for oxygen therapy, oxygen prescription and spirometry data. All patients were using an NC at home before the study and, when asked about what problems they had in the past, the following issues were noted: being uncomfortable (seven patients [28\%]), nasal excoriations (four patients [16\%]), dry nose (one patient [4\%]) and noisy (one patient $[4 \%]$ ).

\section{Oxygen saturation at rest}

Figure 2 shows the saturation values at rest for both the OA and NC. The overall mean baseline saturation while breathing room air was $89 \%$. The saturation increased significantly $(\mathrm{P}<0.001)$ with both oxygen delivery devices at oxygen flow rates of $2 \mathrm{~L} / \mathrm{min}$ and $3 \mathrm{~L} / \mathrm{min}$, and further increases in the oxygen flow rate did not result in any further significant increases in oxygen saturation. The mean saturation (for both devices combined) at $7 \mathrm{~L} / \mathrm{min}$ of oxygen was $97 \%$. The oxygen delivery device did not significantly affect the oxygen saturation $(\mathrm{P}=0.82)$. The breathing pattern at rest did not differ by device, and was found to be $52 \%$ nasal, 28\% mouth and 20\% both nasal and mouth. Breathing pattern (nasal versus mouth) did not affect the oxygen saturation at rest $(\mathrm{P}=0.15)$. The oxygen saturation at baseline did not differ significantly between the first and second treatment periods; there was no residual carry-over effect $(\mathrm{P}=0.44)$. Treatment period (first versus second) did not affect the saturation levels 


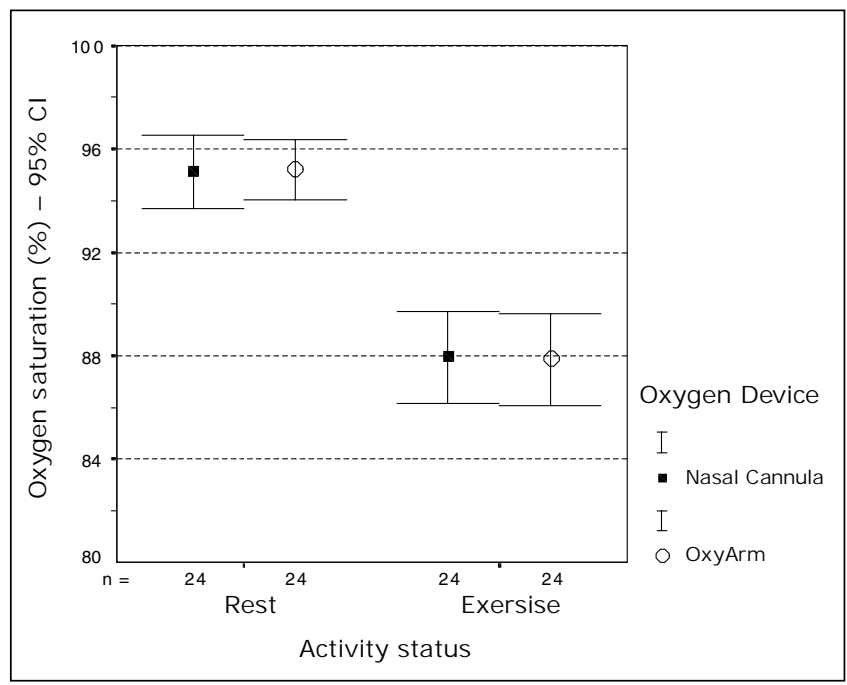

Figure 3) Per cent oxygen saturation at rest and with exercise for both the OxyArm (Southmedic Inc, Canada) and nasal cannula (SalterStyle 1600, Salter Labs, USA). ANOVA showed that the oxygen saturation decreased significantly with exercise $(P=0.02)$; the oxygen delivery device (OxyArm or nasal cannula) did not significantly affect the saturation level $(P=0.83)$; and the device order did not affect the saturation level $(P=0.67)$

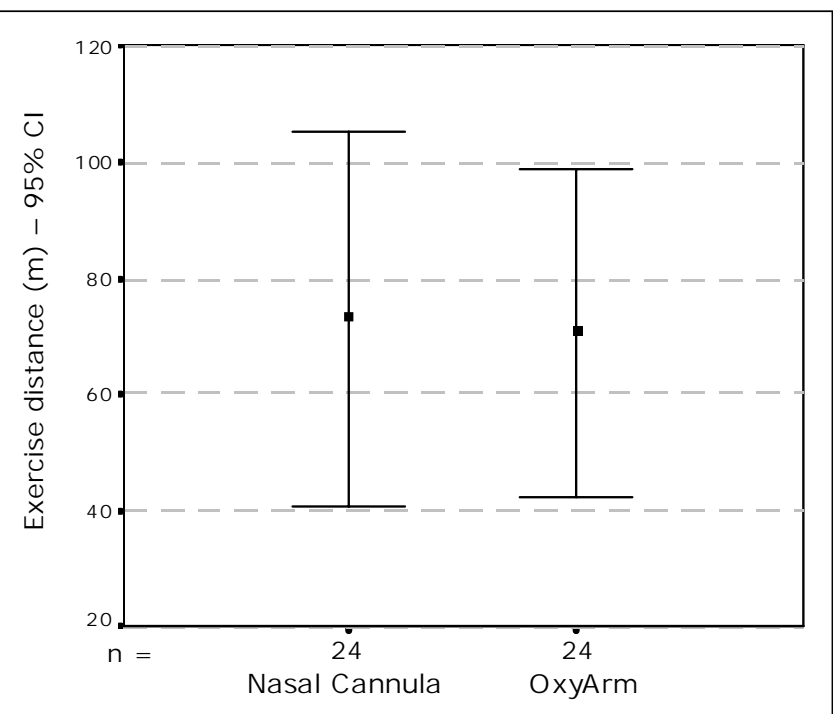

Figure 4) Exercise distance during 5 min walk test for both the OxyArm (Southmedic Inc, Canada) and nasal cannula (Salter-Style 1600, Salter Labs, USA). ANOVA showed that the oxygen delivery device (OxyArm or nasal cannula) did not significantly affect the exercise distance $(P=0.90)$

with oxygen therapy $(\mathrm{P}=0.85)$. There was no period effect. When accounting for the influence of oxygen flow rate, there was no period-by-treatment interaction $(\mathrm{P}=0.99)$.

\section{Exercise performance and saturation}

Figure 3 shows the saturation values at rest and at the end of a 5 min walk test for both the OA and NC. The overall mean saturation at rest was $95 \%$, and this decreased to $88 \%$ following exercise. The oxygen delivery device did not significantly affect the oxygen saturation $(\mathrm{P}=0.83)$. The breathing pattern with exercise did not differ by device, and was found to be $54 \%$ nasal, $29 \%$ mouth and $17 \%$ both nasal and mouth. Breathing

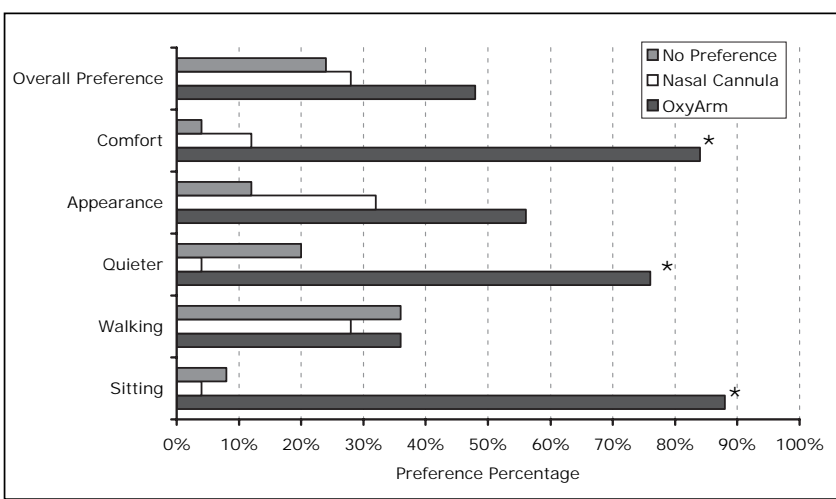

Figure 5) Questionnaire after the acute oxygen therapy trial: oxygen device preference. * Significant preference differences $(P<0.05)$ between the OxyArm (Southmedic Inc, Canada) and nasal cannula (SalterStyle 1600, Salter Labs, USA) based on $\chi^{2}$

pattern did not affect the oxygen saturation while walking $(\mathrm{P}=0.15)$. The treatment period (first versus second) did not influence oxygen saturation $(\mathrm{P}=0.44)$. In addition, there was no treatment-by-period interaction $(\mathrm{P}=0.26)$.

Patients walked a mean of $72 \mathrm{~m}$ (Figure 4) during the $5 \mathrm{~min}$ walk test, and the oxygen delivery device did not significantly affect this distance $(\mathrm{P}=0.90)$.

Reasons for cases of early study discontinuation

Three (12\%) patients did not complete the resting study protocol and, in all of these cases, it was because they could not tolerate oxygen flow rates above $5 \mathrm{~L} / \mathrm{min}$. Twenty-one $(84 \%)$ of the patients did not complete the 5 min walk test; three tests were stopped early because of symptom limitations alone, and the remaining cases were stopped because of oxygen desaturation ( $82 \%$ or lower) and shortness of breath.

\section{Questionnaire after acute oxygen treatment}

At the end of the acute oxygen treatment trial, 21 (84\%) of the patients stated that they would consider the OA for some of their oxygen therapy. Figure 5 shows the results of the questionnaire that was administered immediately after the acute oxygen treatment trial. Significantly more patients preferred the OA for comfort and while sitting, and thought it was subjectively quieter; there was no significant difference for walking, appearance or overall preference. When asked for which situations the OA was best suited, patients described predominantly resting scenarios: watching television (12 patients [48\%]), sitting (10 patients [40\%]), reading (five patients [20\%]) and playing cards (two patients [8\%]). When asked which factor was most important for deciding which oxygen delivery device to use, the majority (19 patients [76\%]) stated their personal experience with the device was the most important factor. Comfort was identified as the most important deciding factor by six (24\%) patients; physician or RT recommendations, clinical studies and appearance were not identified as deciding factors.

\section{Questionnaire after four-week home OA trial}

At the end of the trial, $44 \%$ of the patients stated that they would like to continue to use the OA for some of their oxygen therapy. Significantly more patients preferred the NC overall $(80 \%)$ and while active $(68 \%)$ or eating $(88 \%)$; there were no significant differences in preference for comfort $(54 \%$ for the $\mathrm{NC}$ and $48 \%$ for the $\mathrm{OA}$ ) and for use while resting $(60 \%$ for 
the NC and $40 \%$ for the OA) or driving (56\% for the NC and $24 \%$ for the OA). Several patients $(20 \%)$ did not drive at all. Ten patients $(40 \%)$ stopped using the OA before the end of the four-week trial, the most common reason for stopping was a desire to go back to their standard device. The most common problems identified by patients included difficulties with keeping the device positioned correctly $(80 \%)$, headband discomfort $(40 \%)$ and problems keeping the diffuser out of the way while eating and holding the telephone receiver (36\%).

\section{DISCUSSION}

The strengths of the present study include the use of a priori sample size determination, a randomized crossover design and an objective outcome, namely, pulse oximetry. The crossover design allowed for interpatient comparison of both oximetry and device preference data. In addition, the use of both rest and exercise measurements provided a reasonable estimate of how the devices may perform in everyday use.

This sample of patients was primarily elderly ex-smokers with severe COPD on LTOT for the majority of the day. This sample is similar to the average cross-section of patients in the community who are on LTOT (13). The primary findings were that the $\mathrm{OA}$ and $\mathrm{NC}$ were equally effective in delivering oxygen to patients and maintaining their oxygen saturation at both rest $(\mathrm{P}=0.82)$ and during a 5 min walk test $(\mathrm{P}=0.92)$. Acute oxygen therapy was found to be effective in increasing the oxygen saturation levels from baseline, but the higher oxygen flow rates $(5 \mathrm{~L} / \mathrm{min}, 6 \mathrm{~L} / \mathrm{min}$ and $7 \mathrm{~L} / \mathrm{min})$ were not more effective than an oxygen flow rate of $3 \mathrm{~L} / \mathrm{min}$. These results were robust to the sequence of oxygen delivery device used and to the pattern of breathing (ie, nasal or mouth).

These results are consistent with a previous study that compared oxygen saturation levels in 10 COPD patients who used the $\mathrm{OA}$ and $\mathrm{NC}$ with the oxygen flow set to their usual prescribed rate (8). That study also showed that the oxygen saturation levels achieved with the two devices were not significantly different.

Despite supplemental oxygen therapy, these study patients experienced a modest decrease in oxygen saturation with exercise, from a mean of $95 \%$ at rest to $88 \%$ after the 5 min walk test. The reduced exercise tolerance in these patients was further illustrated by the fact that only four of the 25 patients could complete the $5 \mathrm{~min}$ walk test. Exercise desaturation reflects the fact that these patients had significant lung pathology and could not compensate for the increased oxygen demand during exertion. The cause of exercise intolerance in such patients is multifactorial, and involves an interaction of respiratory, cardiac and peripheral mechanisms (14). Previous studies suggest that the major causes of exercise desaturation in patients with severe COPD are increases in venous admixture and relative hypoventilation during exercise (15). Other studies have documented exercise hypoxemia in patients with lung disease, and the factors found to predict its occurrence include a baseline saturation below $96 \%$ and a low diffusion capacity $(16,17)$.

Although the majority of these patients stated that they were satisfied with their standard NC, some were not $(32 \%)$. After the acute treatment trial, $84 \%$ of the patients were interested in using the OA for some of their LTOT. The subjective feedback on the OA showed that the patients thought that the device was suited for situations in which they were at rest. Following the four-week home OA trial, only 44\% of these patients wanted to continue to use the OA. The most common problem identified with the $\mathrm{OA}$ was related to keeping the device positioned correctly; that is, some patients thought that both the headband and boom were too loose. Headband discomfort was also a common problem. Subsequent to these findings, the vendor made some design modifications to address the stability and headband issues. Specifically, for increased stability, the headband was padded at the pressure points and redesigned to sit at the base of the skull. Further, a chin mount was added for stability as well. This version of the OA was not designed for use during sleep because even with the headband modifications, it would likely not remain in position as people tossed and turned in bed. Another version of the device, with a head strap similar to an oxygen mask, is in development, which could be considered for use during sleep or during anesthesia in spontaneously breathing patients.

Understandably, these patients thought that their personal experience and comfort were the most important factors to consider when choosing an oxygen delivery device. To date, only a few types of oxygen delivery devices have been developed, and the majority of patients on LTOT use a form of NC. Most studies in the past have focused primarily on physiological comparisons, specifically on how oxygen delivery devices compare in their ability to deliver oxygen and maintain oxygen saturation. Surprisingly, patient preferences for oxygen delivery devices have not been explored further. Once a device has proven effective and comparable (or better) in the delivery of oxygen to the $\mathrm{NC}$, then patient satisfaction needs to be considered.

\section{CONCLUSIONS}

The OA proved to be similar to NCs in delivering oxygen and maintaining saturation in patients on LTOT. The OA is a novel device that offers a valuable alternative to patients who do not like or tolerate NCs. Given that most patients on LTOT use oxygen for several hours each day, having an alternate oxygen delivery device may have several advantages. For example, the OA could be used when patients have blocked nasal passages, when they have nasal excoriations or when they want a break from the standard device.

Based on the feedback from the four-week home OA trial, the design of the device was revised to address the issues identified with both the headband and the positioning of the diffuser and boom. Future studies on oxygen delivery devices need to consider patient comfort and preference as key outcomes.

FINANCIAL DISCLOSURE: This trial was funded by a grant from Southmedic Inc, Canada. Analyses were performed and the manuscript was prepared independently of Southmedic Inc.

\section{REFERENCES}

1. Medical Research Council Working Party. Long term domiciliary oxygen therapy in chronic hypoxic cor pulmonale complicating chronic bronchitis and emphysema. Report of the Medical Research Council Working Party. Lancet 1981;1:681-6.

2. Nocturnal Oxygen Therapy Trial Group. Continuous or nocturnal oxygen therapy in hypoxemic chronic obstructive lung disease: A clinical trial. Nocturnal Oxygen Therapy Trial Group. Ann Intern Med 1980;93:391-8.

3. Petty TL. COPD in perspective. Chest 2002;121:116S-20S.

4. Guyatt G, McKim DA, Austin P, et al. Appropriateness of domiciliary oxygen delivery. Chest 2000;118:1303-8.

5. Zielinski J. Long-term oxygen therapy in conditions other than chronic obstructive pulmonary disease. Respir Care 2000;45:172-6. 


\section{Paul and Otvos}

6. Dunne P. The utilization of long-term home oxygen therapy in the United States: A few observations and some suggestions. Respir Care 2000;45:957-61.

7. Bambridge AD. Nasal catheters for oxygen administration. An audit of safety and patient comfort. Br J Theatre Nurs 1993;2:S11-6.

8. Dinesen T, McDonald L, McDonald S, DuVall D. A comparison of the OxyArm oxygen delivery device and standard nasal cannulae in chronic obstructive pulmonary disease patients. Respir Care 2003;48:120-3.

9. McBrien ME, Sellers WF. A comparison of three variable performance devices for postoperative oxygen therapy. Anaesthesia 1995;50:136-8.

10. Bazuaye EA, Stone TN, Corris PA, Gibson GJ. Variability of inspired oxygen concentration with nasal cannulas. Thorax 1992;47:609-11.

11. Muhe L, Degefu H, Worku B, Oljira B, Mulholland EK. Comparison of nasal prongs with nasal catheters in the delivery of oxygen to children with hypoxia. J Trop Pediatr 1998;44:365-8.
12. Ling E, McDonald L, Dinesen TR, DuVall D. The OxyArm A new minimal contact oxygen delivery system for mouth or nose breathing. Can J Anaesth 2002;49:297-301.

13. Okubadejo AA, Paul EA, Wedzicha JA. Domiciliary oxygen cylinders: Indications, prescription and usage. Respir Med 1994;88:777-85.

14. Mitlehner W, Kerb W. Exercise hypoxemia and the effects of increased inspiratory oxygen concentration in severe chronic obstructive pulmonary disease. Respiration 1994;61:255-62.

15. Spence DP, Hay JG, Carter J, Pearson MG, Calverley PM. Oxygen desaturation and breathlessness during corridor walking in chronic obstructive pulmonary disease: Effect of oxitropium bromide. Thorax $1993 ; 48: 1145-50$

16. Knower MT, Dunagan DP, Adair NE, Chin R Jr. Baseline oxygen saturation predicts exercise desaturation below prescription threshold in patients with chronic obstructive pulmonary disease. Arch Intern Med 2001;161:732-6.

17. Hadeli KO, Siegel EM, Sherrill DL, Beck KC, Enright PL. Predictors of oxygen desaturation during submaximal exercise in 8,000 patients. Chest 2001;120:88-92. 


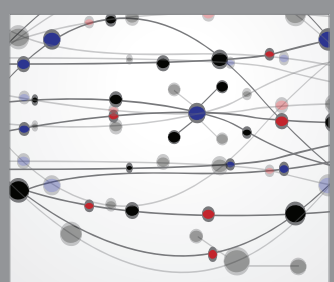

The Scientific World Journal
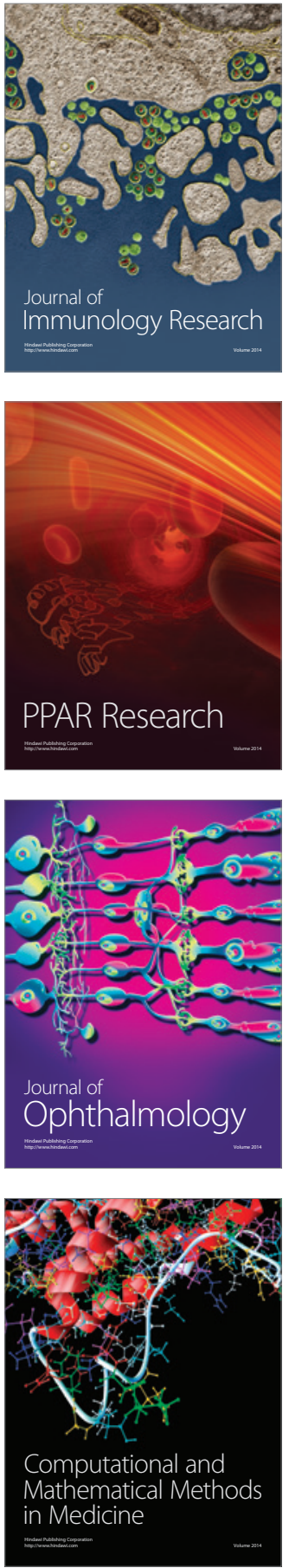

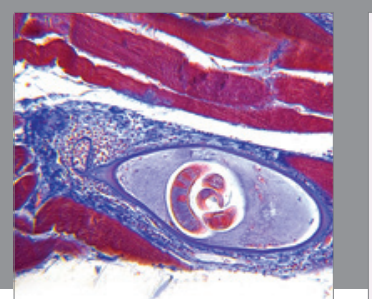

Gastroenterology Research and Practice

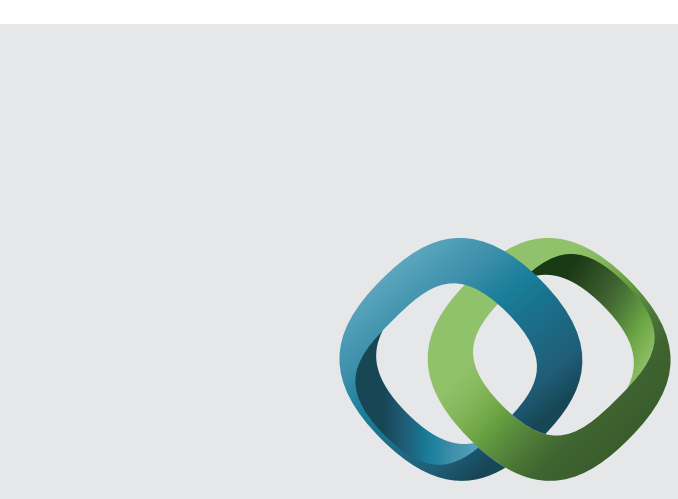

\section{Hindawi}

Submit your manuscripts at

http://www.hindawi.com
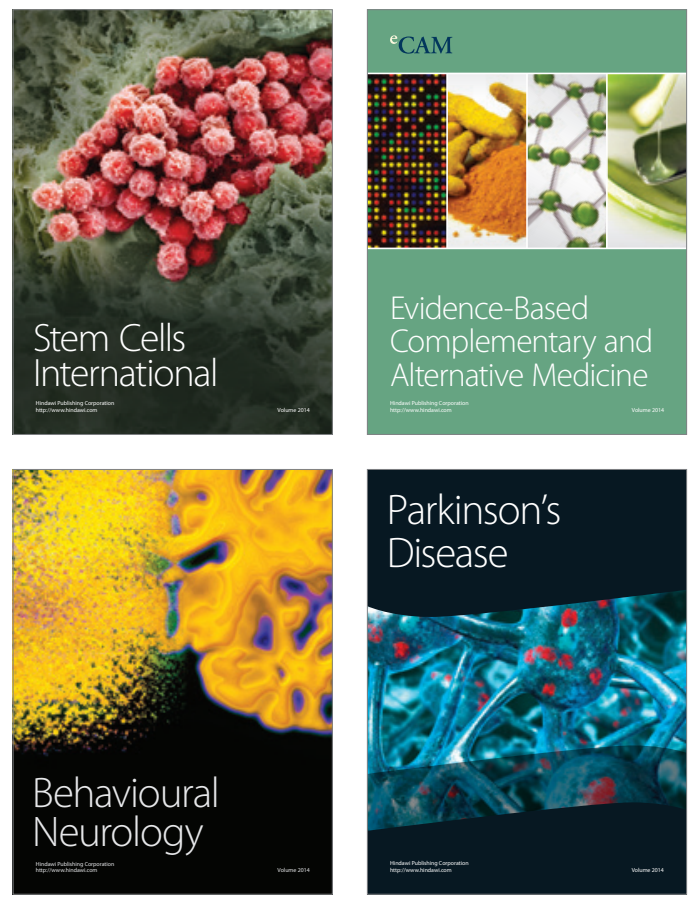
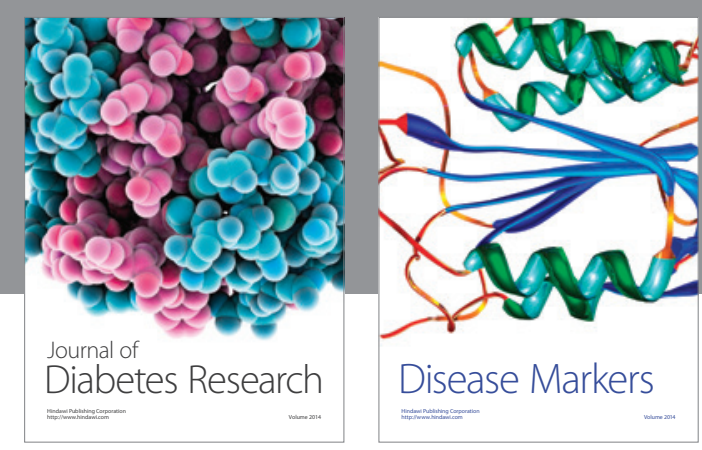

Disease Markers
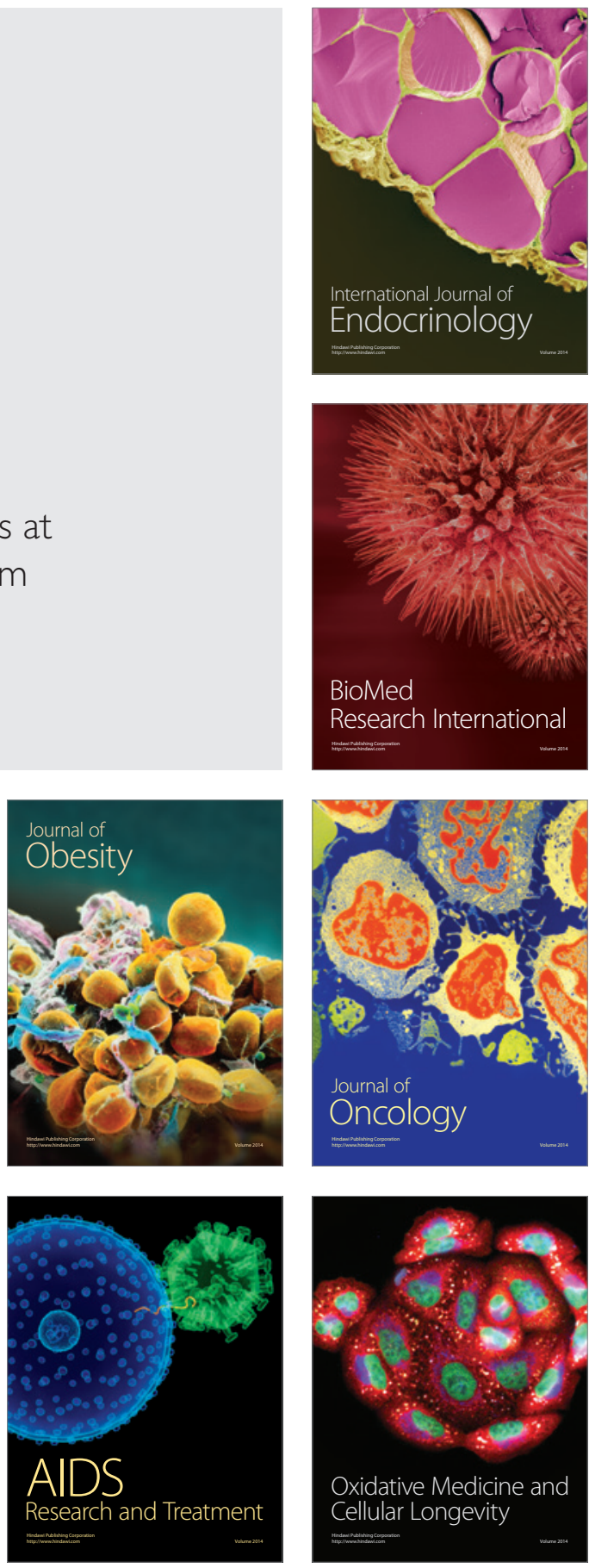